\title{
Intentionality in adherence to long-term therapies. Results from an online survey of 3,00I patients with cardio-metabolic pathologies in France
}

\author{
Gérard Reach (1D' \\ Laurent Benarbia ${ }^{2}$ \\ Eric Bruckert ${ }^{3}$ \\ Jean-Philippe Kevorkian ${ }^{4}$ \\ Michel Farnier ${ }^{5,6}$ \\ Jean-Jacques Mourad ${ }^{7}$ \\ Bernard-Charles Vaisse ${ }^{8}$ \\ 'Health Education and Practices Laboratory \\ (LEPS), Sorbonne Paris-Nord University, \\ Bobigny, France; ${ }^{2}$ Marketing Studio, Paris, \\ France; ${ }^{3}$ Department of Endocrinology and \\ Prevention of Cardiovascular Diseases, \\ Institute of Cardiometabolism and Nutrition \\ (ICAN), La Pitié-Salpêtrière Hospital, AP- \\ HP, Sorbonne University, Paris, France; \\ ${ }^{4}$ Department of Diabetes and \\ Endocrinology, Lariboisière Hospital, \\ Assistance Publique-Hôpitaux de Paris, Paris \\ University, Paris, 75010, France; ${ }^{5}$ PEC2, EA \\ 7460, University of Bourgogne Franche- \\ Comté, Dijon, France; ${ }^{6}$ Cardiology \\ Department, University Hospital Centre of \\ Dijon Bourgogne, Dijon, France; \\ ${ }^{7}$ Department of Internal Medicine and ESH \\ Excellence Centre, Groupe Hospitalier Paris \\ Saint-Joseph, Paris, France; ${ }^{8}$ Hypertension \\ Unit -Vascular Medicine, Department of \\ Cardiology, CHU Timone, Marseille, France
}

Correspondence: Gérard Reach Health Education and Practices Laboratory (LEPS), Sorbonne Paris-Nord University, 74 rue Marcel Cachin, Bobigny, 93017, France

Tel +33660845325

Email gerardreach@icloud.com
Purpose: Some patients make a rational choice not to follow medical prescriptions; others fail to take their medications for reasons beyond their control, such as mere forgetfulness or a weak medication routine. The aim of this study was to elucidate the functioning of patient intentionality in medication adherence.

Patients and Methods: This online study was conducted in metropolitan France in 2019. A cross-sectional survey of 50 questions was conducted with 3001 respondents diagnosed with diabetes, hypertension, and/or hypercholesterolemia identified from a panel of 54,000 people. These questions included a validated six-item questionnaire to detect nonadherence, two questions to detect intentional nonadherence by patients, and three questions on the effects of habit. Our questionnaire also included questions on the feelings of respondents regarding their doctor's attitude to their problems and needs, their trust in general practitioners (GP) and specialists, their sense of being involved in treatment decisions, and the influence of side effects and habits on patients' adherence. This study used the strategy of focusing on strictly adherent patients in the hope of finding ways to improve adherence. For this reason, we defined adherence as the absence of a positive response to the 6-item nonadherence screening questionnaire.

Results: Of 3001 respondents, 1804 were diagnosed with hypertension, 1458 with hypercholesterolemia, and 774 with diabetes. Of the total number of patients, $72 \%$ were afflicted with one disease, $21 \%$ with two ailments, and $7 \%$ with three simultaneous illnesses. One-third (33\%) of the patients did not tender a positive answer to the adherence questionnaire and were deemed adherent. 1) Thirty-two percent of the patients reported occasionally omitting their medication deliberately, and $84 \%$ said they had a reason for missing doses. These statements suggesting intentional nonadherence were negatively associated with adherence as identified via multivariate analysis $(\mathrm{P}=0.0012$ and $\mathrm{P}<0.0001$, for the first and second statement, respectively). 2) Univariate analyses revealed strong associations $(\mathrm{P}<0.0001)$ between strict adherence on one hand and lack of intentional nonadherence, patient age, absence of drug side effects, taking drugs by habit, feeling involved in treatment decisions, getting information about treatment, and disease, and trust in doctors, on the other hand. 3) Specifically, univariate analysis of the absence of reported side effects revealed strong associations $(\mathrm{P}<0.0001)$ with adequate information about medicines and diseases and trust in GP. These original data were consistent with the concept of the nocebo effect. 4) We observed a strong association between the absence of intentional nonadherence (statement of never deliberately missing medication) and respondent statements about generally sticking to the routine $(\mathrm{P}<0.0001)$, ie, "I take my medication because I am used to taking it." This important result suggests that patients are strictly adherent in two ways: the absence of intentional nonadherence and reliance on habit, which we term as "unintentional adherence." 5) Finally, a multiple correspondence analysis illustrated all statistically significant relationships found in this study. 
Conclusion: We present a new global model of adherence in which patient adherence was improved both by reducing intentional nonadherence and by promoting the abovementioned unintentional adherence by habit. This model highlights the role of shared decision-making and the trust felt by patients in their doctors. These results could exert a major impact on medical practice and education by demonstrating the importance of physicians' attitudes, involving the patient in decisions (shared decision-making), offering information about medicines and diseases (patient education), understanding the problems of patients, and taking their needs into account (empathy). The development of these attitudes should be an important aspect of the medical curricula.

Keywords: adherence; intentionality; intentional; unintentional, doctor-patient relationship, shared medical decision, trust, habit, side effects of drugs

\section{Introduction}

Decades of study ${ }^{1,2}$ have investigated patients' nonadherence to medical treatment because of its frequency ${ }^{3-8}$ and consequences for morbidity, mortality, and health costs. ${ }^{9-16}$ Vrijens et al posited that adherence could be described through three phases: initiation, implementation, and discontinuation. ${ }^{2}$ Studies have related multiple determinants of nonadherence involving the nature of the disease, the treatment, patient characteristics, and quality of physician-patient relationships. ${ }^{17-22}$

The distinction between intentional and unintentional nonadherence was an important step in understanding the phenomenon, ${ }^{23}$ elucidating that some patients rationally chose not to follow medical prescriptions while others neglected their prescribed doses for reasons beyond their control, for instance, forgetting or weaker medicationtaking routines, or habit strengths. ${ }^{24}$ Notably, the frequency of unintentional nonadherence increases during the first six months, while intentional nonadherence remains relatively stable. ${ }^{25}$ One study found that intentional nonadherence was more common among people with high literacy levels, while unintentional nonadherence was more widespread in people with low literacy. ${ }^{26}$ However, the distinction between intentional and unintentional nonadherence may be more subtle than the mere deeming of the former as an active decision by patients and the latter as a passive process. One study suggested that unintentional nonadherence was statistically associated with beliefs about medication, indicating that unintentional nonadherence could mediate between beliefs about the medication and intentional nonadherence. An episode of unintentional nonadherence can offer patients the opportunity to test the consequences of not taking the prescribed drug, which could subsequently reinforce the decision to shift to intentional nonadherence. ${ }^{27}$

Whether the adherence of patients who take their medications as prescribed can also be subject to such a distinction then becomes relevant: is adherence always intentional? Is it always motivated by the desire to stay healthy or to avoid complications of a disease? Conversely, can it, in certain cases, not follow the formation of an intention? The possibility of "unintentional adherence" causes contemplation of the role of habit in adherence, reflecting the originality of Triandis' interpersonal behavior model. ${ }^{28}$ This framework has been empirically supported; ${ }^{29,30}$ one study has explicitly associated the absence of habit with unintentional nonadherence. ${ }^{24}$ A conceptual mechanism of the impact of habit on adherence has been proposed by the first author of this paper. ${ }^{31}$ Strength of habit may avoid reliance on patient intention to take medication, ${ }^{32}$ which requires cognitive effort. Daniel Kahneman, winner of the Nobel Prize in Economics in 2002 and one of the founders of behavioral economics, postulated that humans display two types of thinking: Type 1 is rapid and unconscious, relies on habit, and uses heuristics, ie, short circuits of reasoning; Type 2 is conscious, takes into account all arguments, and therefore, requires cognitive effort. Habit minimizes effort and would thus be designated to Type 1 of Kahneman's system of cognition. ${ }^{33}$

This article presents a study of a large population of patients suffering from cardio-metabolic diseases aiming to empirically determine the conditions that make a patient intentionally or unintentionally adherent. It therefore posits questions of intentionality in adherence. What are the determinants of intentional nonadherence and unintentional adherence? How does intentionality relate to the attitudes of doctors, perceptions of patients, and placing of trust in the physician-patient relationship?

Most studies on adherence query the causes of nonadherence; this study used the unusual strategy of focusing on the causes of adherence. In other words, we examined how adherence to medication is possible. Answering this question should offer insights into how to improve adherence if necessary. ${ }^{34}$ This study documents the strong links between adherence-including the absence of intentional 
nonadherence - and side effects of drugs, quality of physician-patient relationships, feelings of patients apropos their involvement in their treatment decisions, and functions of habit. The study generates a comprehensive new model describing the two sides of adherence, illuminating the absence of intentional nonadherence and the presence of unintentional adherence, and demonstrating their associations with physician attitudes and the quality of the physician-patient relationship.

\section{Patients and methods}

\section{Patients}

They were recruited from the NORSTAT panel ${ }^{35}$ of 54,000 consumers (response rate: $40 \%$ ), generally responding to marketing/media studies but also ( $8 \%$ of the studies) to issues concerning their health. A generic email invitation to participate ("respond to a survey") did not indicate the nature of our study. The survey began with a question to identify patients suffering from hypertension, hypercholesterolemia, and/or type 2 diabetes. Those identified received a login code for completing an online questionnaire. Participants understood NORSTAT's extensive quality controls, including the impossibility for one person to register under several accounts or email addresses and analysis of participants' response times.

\section{Questionnaire}

A questionnaire detected nonadherence as described by Girerd et al. ${ }^{36}$ This questionnaire was validated with people diagnosed with hypertension and is recommended by the French Health Authorities to screen for nonadherence in people with chronic diseases. It included six questions, such as "This morning did you forget to take your medicine?" Zero positive responses indicate good adherence; one or two, minimal nonadherence; and three or more severe nonadherence. We dichotomized the data by separating the patients giving no positive response from the others, thus creating two groups of patients, called adherent and nonadherent, respectively. As mentioned above, our research strategy was indeed to determine the factors associated with strict adherence (no positive answer in the adherence questionnaire) so that we could identify ways to improve adherence when necessary. According to this definition, 33\% patients who did not offer a positive answer to the adherence questionnaire were considered adherent.
In addition to the six questions of Girerd's questionnaire, the questionnaire (see Appendix) compiled the demographic data of patients (six questions), identified their pathologies of interest (type 2 diabetes, hypertension, and/or hypercholesterolemia, plus other chronic pathologies) and their duration (three questions), and details of treatment (five questions on the number of prescribed medications, daily doses, and injectable medicines). In addition, the questionnaire was designed to answer the research question about the place of intentionality in adherence. It thus included questions intended to test the role of intentional nonadherence, habit, and elements that could be assumed to explain both intentional and unintentional nonadherence, and features that could serve as classic determinants: age, attitudes of doctors, trust, treatment characteristics, and particularly, adverse effects. As shown below, the questionnaire was based on existing literature and the first author's previous studies. Thus, no pilot test was performed to ensure the comprehension of the items.

Two questions identified intentional nonadherence ("Do you sometimes deliberately not take your medications?" and "When you sometimes do not take your medication, can you give the reason why?"). ${ }^{27}$ One question explored the reasons for not taking the medication with multiple choices for responses. Seven questions explored patients' attitudes toward medications and their side effects, and the merits of lifestyle and diet. Four questions explored whether habit formation influenced taking medications and engaging in physical activity ${ }^{29}$ and the strength of habit ("Generally speaking, when you are in the habit of doing something, do you stick to it?"). ${ }^{30}$ Five questions also explored relations between patients and their doctors (GP, specialists, diabetologists, and cardiologists), patients' trust in physicians and doctors' attitudes toward patients' requests and needs. ${ }^{37}$ In particular, one question explored whether the patients felt involved in their treatment. ${ }^{37}$ Finally, two questions attempted to ascertain the sufficiency of information about pathology and treatment.

\section{Statistics}

We employed a univariate and multivariate analyses to identify factors involved in adherence/nonadherence to medication. A univariate analysis, including only nonadherent patients $(n=2022)$ to avoid circularity, explored determinants of intentional nonadherence. Univariate analyses of the whole cohort $(n=3001)$ also explored patients' answers associated with having experienced 
medication side effects and the role of habit in taking medication. Finally, we performed a multiple correspondence analysis (MCA) to illustrate visually the links between areas studied and adherence or nonadherence.

Some questions used a four-choice Likert scale, such as strongly agree, somewhat agree, somewhat disagree, strongly disagree. This study examined factors associated with strict adherence (not one positive answer in the 6-item adherence questionnaire), complete lack of intentional nonadherence (answering never to the question), absence of side effect reporting, strong agreement with the propositions that they trust their physicians, or that they take their medication out of habit. This mode of dichotomization was used both in univariate analyses and in the MCA.

\section{Data anonymity, ethics, and conformity to publication reporting guidelines}

NORSTAT panels conform strictly to General Data Protection Regulation directives concerning data confidentiality and to European Society for Opinion and Market Research standards. ${ }^{38}$ Completing a questionnaire implies consent to participate in the study. Questionnaires in studies of social and human sciences fall outside France's Jardé law regulating the ethics of clinical research and require no prior approval by an ethics committee. Nevertheless, our study received an approval from an institutional review board (Comité Local d'Ethique pour la Recherche Clinique des HUPSSD Avicenne), CLEA2020-165. This study conforms to STROBE guidelines.

\section{Results}

\section{Description of patients and responses}

From October to November 2019, 3001 patients, evenly divided by gender (49\% male vs $51 \%$ female) with an average age of 55.7 years (median 56.8, age distribution: <35: 7\%; 35-49: 24\%; 50-59: 26\%; 60-65: 20\%; 66 and more: $24 \%$ ), responded to the questionnaire. Of that number, 1804 presented with hypertension, 1458 with hypercholesterolemia, and 774 with diabetes. Totals exceed 3001 as $72 \%$ of the patients presented with one pathology, $21 \%$ with two, and $7 \%$ with three simultaneously. Approximately $11 \%$ of patients had been diagnosed with their longest-term condition for less than six months, $14 \%$ for one to two years, and $75 \%$ for more than two years. In addition, 401 patients (13\%) had been prescribed injectable drugs.

Overall, $33 \%$ of the patients gave no positive answer to the adherence questionnaire (strict adherence) and were categorized as adherent for the analysis, 52\% gave one or two positive responses (minimal nonadherence), and $16 \%$ gave three to six positive responses (severe nonadherence). Thus, $67 \%$ of the patients qualified as nonadherent; $32 \%$ stated that they sometimes did not adhere to the treatment deliberately; and $60 \%, 15 \%, 9 \%$, and $16 \%$ respectively said that they could "most often," "quite often," "rarely," or "never" offer reasons for not taking their medication. Of the patients, $65 \%$ did not report side effects from medication.

Only $42 \%$ and $31 \%$ of the patients could "strongly agree" that they had received enough information about their conditions and medicines, respectively. $44 \%$ to $62 \%$ of patients could "strongly agree" that they feel involved in treatment decisions and that their doctor or specialist understands the problems related to their treatment and takes their needs into account. In addition, $77 \%$ and $65 \%$ of patients could "strongly agree" that they trust their GP or specialist, respectively, and $41 \%$ could "strongly agree" that the relationship with their doctor influenced whether they took their medication as prescribed.

The overwhelming majority of patients (92\%) persisted in their habits, and 44\% "strongly agreed" that they took their medication as a habit; $24 \%$ "strongly agreed" that they exercise as a habit.

\section{Determinants of Adherence}

A total of $979(33 \%)$ patients did not tender any positive answers to the 6-item adherence questionnaire. The univariate analysis and descending significance (Test-value) associated this strict adherence $(P<0.0001)$ with patients who did not experience the side effects of the medication (Test-value $=15.85)$, who strongly believed their medications were beneficial (Test-value $=11.52$ ), believed their general practitioner fully understood their treatment problems (Test-value $=7.57$ ), could not offer reasons for not taking treatment (Test-value $=7.43$ ), did not take injectable medication (Test-value $=6.97$ ), felt "fully informed" about their pathology (Test-value $=6.90$ ), were 66 or older (Test-value $=6.23$ ), believed their physician attended to their needs (Test-value $=6.43$ ) and agreed unreservedly with the statement that they trusted their general practitioner (Test-value $=5.35)$. Hypertensive patients who only took medication once daily (Test-value $=3.67$ ) and who only took one tablet (Test-value $=4.09$ ) were more likely to be adherent, as were patients who do not take injectables $($ Test-value $=6.97)$. 
Inversely, nonadherence was associated with being 35-49 (Test-value $=4.73$ ), taking medications at noon or in the evening (Test-value $=7.96$ and 5.33, respectively), with declaring both rarely or quite often not taking deliberately the medications (Test-value $=7.67$ and 11.67 , respectively), with answering "somewhat agreeing" to the question "to what extent would you say there is a trust relationship between you and your GP and specialist" (Test-value $=4.56$ and 5.49, respectively).

The multivariate analysis and descending odds ratio identified several determinants that were positively $(\mathrm{OR}>1)$ associated with adherence by patients: the feeling that the specialist does not take patient's needs into account $(\mathrm{OR}=3.5450,95 \%$ CI $1.3970-8.9960, P=0.0284$ ), being adequately informed about the medication (OR $=2.022,95 \%$ CI $1.4960-2.7310$, $P<0.0001)$, feeling that the medication is beneficial ( $\mathrm{OR}=$ $1.5060,95 \%$ CI $1.0110-2.2440, P=0.0440$ ), and the last occupational designation of executive $(\mathrm{OR}=1.2880,95 \% \mathrm{CI}$ $=1.0350-1.6030, P=0.0233)$. Other determinants were negatively $(\mathrm{OR}<1)$ associated with adherence: a nonoptimal relationship of trust with the specialist $(\mathrm{OR}=0.1810,95 \% \mathrm{CI}$ $0.0740-0.4440, P=0.0009$ ), agreement with the statement that side effects represent a reason for not taking the medication regularly $(\mathrm{OR}=0.3680,95 \% \mathrm{CI}=0.2230-0.6080, P=0.0012)$, declaration of often deliberately avoiding the medication $(\mathrm{OR}=$ $0.4680,95 \%$ CI $0.2960-0.7400, P=0.0012$ ), assertion of having experienced side effects from the medication(s) $(\mathrm{OR}=$ $0.4760,95 \% \mathrm{CI}=0.3560-0.6360, P<0.0001$ ), not following the pharmacist's advice to undertake regular physical activity $(\mathrm{OR}=0.5280,95 \% \mathrm{CI}=0.3160-0.8810, P=0.0194)$, the ability to offer a rationale for not taking the medication (OR = $0.5490,95 \% \mathrm{CI}=0.4420-0.6820, P<0.0001)$, being aged 53 $70(\mathrm{OR}=0.6250,95 \% \mathrm{CI}=0.4800-0.8150, P=0.0026)$, registering disagreement with the statement that side effects of medications denote a valid reason for not taking the medication regularly $(\mathrm{OR}=0.6450,95 \% \mathrm{CI}=0.4260-0.9770, P=0.0004)$, adopting special tricks to ensure taking the medication daily $(\mathrm{OR}=0.6530,95 \% \mathrm{CI}=0.5120-0.8340, P=0.0006)$, and sharing a medical condition with a family member $(\mathrm{OR}=$ $0.7970,95 \% \mathrm{CI}=0.6670-0.9530, P=0.0128$ ).

\section{Determinants of the response "Never" to the question "Do you ever deliberately not take your medication?"}

This analysis shown in Table 1 pertains only to nonadherent patients $(\mathrm{n}=2022)$. Of these, $1778 \quad(87.9 \%)$ answered "never" to the question "Do you ever deliberately not take your medication?". This answer was associated with numerous characteristics $(P<0.0001$ unless specified $)$ : patients do not take injectables $($ Test-value $=11.16)$, do not experience adverse reactions to medications (Test-value $=7.41$ ), and believe their medications are beneficial (Test-value $=7.20$ ). They are generally over age 53 (Test-value $=7.01$ ). They cannot specify why they did not take their medication (Testvalue $=5.96)$. They feel their GP and specialists consider their needs and understand the problems associated with the treatment (Test-values all $>5$ ). Having formed a habit, they stick to it (Test-value $=4.95)$. They trust their specialist (Test-value $=2.71, P=0.003$ ), feel involved in treatment decisions $($ Test-value $=2.62, P=0.004)$, and feel sufficiently informed about their pathology (Test-value $=2.25$, $P=0.012)$.

\section{Determinants of the Response "No" to the question "Have you experienced side effects from your medication(s)?"}

This negative response was given by 1956 patients $(65.18 \%)$. It is strongly associated $(P<0.0001)$ with adherence (Test-value $=15.85)$, with never deliberately omitting a dose (Test-value $=9.76$ ), being able to offer a reason for not taking the medication (Test-value $=15.49$ ), feeling informed about the drug (Test-value $=7.92$ ) and the pathology (Test-value $=6.42$ ), feeling that the GP understands the treatment-related problems (Test-value $=7.75$ ) and takes the patient's needs into account (Test-value $=7.16$ ), and forging a trusting relationship with the GP (Test-value $=4.29$ ). It is associated with a beneficial view of the medication (Testvalue $=6.10$ ). In addition, being between 53 and 70 years of age (Test-value $=3.25, P=0.001$ ), exercising (Test-value $=$ 2.56, $P=0.005$ ) and taking medication out of habit (Testvalue $=2.08, P=0.019$ ), and being male (Test-value $=2.17$, $P=0.015)$ were also found associated with the absence of side effects.

\section{The role of habit}

Ninety-two percent (2772 patients) answered positively to the question, "Generally speaking, when you get into the habit of doing something, do you stick to it?" In descending significance order, the most significant factors (Test-value $>5, P<0.0001$ ) are feeling involved in decisions (Test-value $=8.01$ ), believing GP understands patient's treatment problems (Test-value $=7.32)$, being sufficiently informed about the pathology (Test-value $=$ 6.53), believing specialist takes into account their needs 
Table I Univariate Analysis of the Absence of Intentional Nonadherence

\begin{tabular}{|c|c|c|c|}
\hline Do you sometimes deliberately not take your medication? & & & \\
\hline Never $(n=1778$ out of 2022 nonadherent patients) (87.9\%) & & $\begin{array}{l}\text { Test- } \\
\text { value }\end{array}$ & $\mathbf{P}$ \\
\hline $\begin{array}{l}\text { Have you ever stopped taking your treatment because, on some days, you feel your treatment is doing } \\
\text { more harm than good? }\end{array}$ & No & 18.38 & $<0.0001$ \\
\hline Did you forget to take your medication this morning? & No & 12.51 & $<0.0001$ \\
\hline If you are concerned, how many times do you need to take an injection? & Injectable: No & 11.16 & $<0.0001$ \\
\hline Have you run out of medication since the last visit? & No & 9.32 & $<0.0001$ \\
\hline Has your doctor or pharmacist advised you about proper nutrition? & No & 7.81 & $<0.0001$ \\
\hline Have you experienced side effects from your medication(s)? & No & 7.41 & $<0.0001$ \\
\hline What is your vision of the benefit of your medication? & Beneficial & 7.20 & $<0.0001$ \\
\hline How old are you? & $53-70$ & 7.01 & $<0.0001$ \\
\hline Are you currently employed? (several possibilities given) & No & 6.77 & $<0.0001$ \\
\hline When was this (these) condition(s) diagnosed? Hypertension & $>6$ months & 6.76 & $<0.0001$ \\
\hline Which of the following people support you in taking your medication(s) correctly? Nurse & $\begin{array}{l}\text { Not } \\
\text { concerned }\end{array}$ & 6.50 & $<0.0001$ \\
\hline How many times per day must you take medication for this (these) condition(s)? Hypertension & Once daily & 6.24 & $<0.0001$ \\
\hline How many tablets or capsules (by mouth) do you take per day for this/these condition(s)? Hypertension & One & 5.97 & $<0.000$ I \\
\hline When you sometimes do not take your medication, can you give the reason why? & No & 5.96 & $<0.0001$ \\
\hline When you sometimes do not take your medication, can you give the reason why? & Never & 5.96 & $<0.0001$ \\
\hline To what extent do you feel your GP understands problems with your treatment? & Understands & 5.88 & $<0.000$ I \\
\hline Have you ever not taken your medication because you had a memory lapse on certain days? & No & 5.83 & $<0.0001$ \\
\hline Do you have other tricks for taking your medication every day? & No & 5.69 & $<0.0001$ \\
\hline To what extent do you feel that your GP takes your needs into account? & $\begin{array}{l}\text { Takes into } \\
\text { account }\end{array}$ & 5.49 & $<0.0001$ \\
\hline "I do a physical activity because I am used to doing it." & Disagree & 5.46 & $<0.0001$ \\
\hline What disease(s) do you suffer from? & Hypertension & 5.29 & $<0.0001$ \\
\hline Generally speaking, when you are in the habit of doing something, do you stick to it? & Yes & 4.95 & $<0.0001$ \\
\hline Has your pharmacist advised you to be physically active on a regular basis? & No & 4.78 & $<0.0001$ \\
\hline Which of the following people support you in taking your medication(s) correctly? Friends & $\begin{array}{l}\text { Not } \\
\text { concerned }\end{array}$ & 4.50 & $<0.0001$ \\
\hline Do you think you have too much medication to take? & No & 4.44 & $<0.0001$ \\
\hline Q46 Which of the following people support you in taking your medication(s) correctly? Children & $\begin{array}{l}\text { Not } \\
\text { concerned }\end{array}$ & 4.42 & $<0.0001$ \\
\hline How old are you? & 70 and more & 3.81 & $<0.0001$ \\
\hline Are side effects one reason you do not take your medication regularly? & Disagree & 3.48 & $<0.0001$ \\
\hline
\end{tabular}


Table I (Continued).

\begin{tabular}{|c|c|c|c|}
\hline Which of the following people support you in taking your medication(s) correctly? Spouse & $\begin{array}{l}\text { Not } \\
\text { concerned }\end{array}$ & 3.41 & $<0.0001$ \\
\hline Has your doctor or pharmacist advised you about proper nutrition? & No & 3.35 & $<0.0001$ \\
\hline Do you share a medical condition(s) with a family member(s)? & No & 3.22 & 0.0006 \\
\hline Do you follow their advice? & No & 2.89 & 0.0019 \\
\hline "I take my medication because I'm used to taking it." & Agree & 2.87 & 0.0020 \\
\hline $\begin{array}{l}\text { How many tablets or capsules (by mouth) do you take per day for this/these condition(s)? } \\
\text { Hypercholesterolemia }\end{array}$ & One & 2.80 & 0.002 \\
\hline To what extent would you say there is a relationship of trust between you and your specialist? & Trust & 2.71 & 0.003 \\
\hline To what extent do you feel involved in decisions about your treatment? & Involved & 2.62 & 0.004 \\
\hline $\begin{array}{l}\text { Would you say that your relationship with your doctor influences whether you are taking your } \\
\text { medications correctly? }\end{array}$ & Disagree & 2.51 & 0.005 \\
\hline To what extent do you feel adequately informed about your pathology(ies)? & Informed & 2.25 & 0.012 \\
\hline To what extent do you feel your specialist understands problems with your treatment? & Understands & 2.1395 & 0.016 \\
\hline How many times per day must you take medication for this (these) condition(s)? Hypercholesterolemia & Once daily & 2.13 & 0.016 \\
\hline
\end{tabular}

Notes: Determinants, in descending order of significance, of the response "never" to the question: Do you sometimes deliberately not take your medication?

(Test-value $=6.52$ ), being able to give the reason for not taking the medication (Test-value $=5.82$ ), never missing medication deliberately (Test-value $=5.48$ ), agreeing with the proposition of having trust in the GP (Testvalue $=5.48)$, being 53 or more (Test-value $=3.99$ ), being sufficiently informed about medication (Testvalue $=5.26)$. Male patients seem more likely to stick to habits (Test-value $=2.68, P=0.003$ ). Finally, being treated for hypertension longer than six months associates positively with sticking to habits (Test-value $=2.11$, $P=0.017)$.

There were 1325 patients $(44.15 \%)$ who fully agreed with the statement: "I take my medication because I am used to taking it." Table 2 shows that this response is associated with practicing physical activity by habit (Testvalue $=5.24$ ) and has essentially the same determinants as those associated with the strength of habit seen above, including adherence to medication, never missing medication deliberately, feeling informed about the pathology and medications, being involved in decisions, and having a positive attitude toward physicians.

\section{Multiple Correspondence Analysis}

These data indicate clear connections among age, adherence in general, intentional nonadherence in particular, experiencing adverse effects of medication, taking medication out of habit, feeling involved in treatment decisions, and trusting one's general practitioner or specialist. These connections appear in Figure 1, which presents results of MCA of these domains, allowing separation between adherent (1) and nonadherent patients (2). It is noteworthy that the lines describing intentional nonadherence $(\mathrm{C} 1-\mathrm{C} 2)$, experiencing side effects (D1-D2), and age (A1-A2) appear close to the line describing adherence (B1-B2), revealing the importance of these determinants. The two lines concerning the fidelity to habit (E1-E2) and taking medication out of habit (I1-I2) are superposed. They are proximate to the lines describing trust in the GP (G1-G2) and the specialist $(\mathrm{H} 1-\mathrm{H} 2)$ and the feeling of being involved in decisions (F1-F2).

\section{Discussion}

This study purposely examined factors associated with strict adherence (no one positive answer in the 6-item adherence questionnaire), complete lack of intentional nonadherence (answering "never" to the question), absence of side effect reporting, strong agreement with the propositions that patients trust their physicians, or that they take their medication out of habit. 
Table 2 Univariate Analysis of the Effect of Habit

\begin{tabular}{|c|c|c|c|}
\hline $\begin{array}{l}\text { How much do you agree with the following statement about taking your medication? "I } \\
\text { take my medication because I am used to taking it." }\end{array}$ & & & \\
\hline \multicolumn{4}{|l|}{ Fully agree $(n=1325,44.15 \%)$} \\
\hline & & Test-value & $\mathbf{P}$ \\
\hline Do you sometimes deliberately not take your medication? & Never & 10.84 & $<0.0001$ \\
\hline $\begin{array}{l}\text { Have you ever stopped taking your treatment because, on some days, you feel your treatment is doing } \\
\text { more harm than good? }\end{array}$ & No & 7.60 & $<0.0001$ \\
\hline What is your vision of the benefit of your medication? & Beneficial & 7.54 & $<0.0001$ \\
\hline Have you ever taken your medication later than usual? & No & 5.41 & $<0.000$ I \\
\hline Generally speaking, when you are in the habit of doing something, do you stick to it? & Yes & 5.31 & $<0.0001$ \\
\hline "I do a physical activity because I am used to doing it." & Agree & 5.24 & $<0.0001$ \\
\hline Have you ever not taken your medication because you had a memory lapse on certain days? & No & 5.04 & $<0.0001$ \\
\hline Adherent/nonadherent & Adherent & 4.95 & $<0.0001$ \\
\hline To what extent do you feel adequately informed about your pathology(ies)? & Informed & 4.90 & $<0.0001$ \\
\hline Did you forget to take your medication this morning? & No & 4.60 & $<0.0001$ \\
\hline To what extent do you feel your GP understands problems with your treatment? & Understands & 4.57 & $<0.0001$ \\
\hline To what extent do you feel that your GP takes your needs into account? & $\begin{array}{l}\text { Takes into } \\
\text { account }\end{array}$ & 4.54 & $<0.0001$ \\
\hline To what extent do you feel adequately informed about your medication(s) & Informed & 4.40 & $<0.0001$ \\
\hline When was this (these) condition(s) diagnosed? Hypertension & $\begin{array}{l}\text { More than } 6 \\
\text { months }\end{array}$ & 4.03 & $<0.000$ I \\
\hline $\begin{array}{l}\text { What disease(s) do you suffer from (several possibilities given, Hypertension, Cholesterol, Type } 2 \\
\text { Diabetes, None of these)? }\end{array}$ & Hypertension & 3.90 & $<0.0001$ \\
\hline When you sometimes do not take your medication, can you give the reason why? & I can & 3.87 & $<0.0001$ \\
\hline When you sometimes do not take your medication, can you give the reason why? & I cannot & 3.75 & $<0.0001$ \\
\hline When was this (these) condition(s) diagnosed? Diabetes & $\begin{array}{l}\text { More than } 6 \\
\text { months }\end{array}$ & 3.45 & $<0.0001$ \\
\hline To what extent would you say there is a relationship of trust between you and your GP? & Trust & 3.42 & $<0.0001$ \\
\hline What disease(s) do you suffer from? & Diabetes & 3.33 & $<0.0001$ \\
\hline $\begin{array}{l}\text { How many tablets or capsules (by mouth) do you take per day for this/these condition(s)? } \\
\text { Hypertension }\end{array}$ & $\begin{array}{l}\text { More than } \\
\text { one tablet }\end{array}$ & 3.28 & 0.0005 \\
\hline To what extent do you feel involved in decisions about your treatment? & Involved & 3.10 & 0.0009 \\
\hline How old are you? & 53 and more & 3.07 & 0.0010 \\
\hline How many times per day must you take medication for this (these) condition(s)? Hypertension & $\begin{array}{l}\text { More than } \\
\text { once daily }\end{array}$ & 2.97 & 0.0014 \\
\hline How many times per day must you take medication for this (these) condition(s)? Diabetes & $\begin{array}{l}\text { More than } \\
\text { once daily }\end{array}$ & 2.88 & 0.0019 \\
\hline
\end{tabular}


Table 2 (Continued).

\begin{tabular}{|c|c|c|c|}
\hline Have you experienced side effects from your medication(s)? & No & 2.77 & 0.0027 \\
\hline How many times per day must you take medication for this (these) condition(s)? Hypertension & Once daily & 2.64 & 0.0041 \\
\hline Are you currently employed? & No & 2.60 & 0.0046 \\
\hline How many times per day must you take medication for this (these) condition(s)? Hypercholesterolemia & Once daily & 2.52 & 0.0057 \\
\hline How many times per day must you take medication for this (these) condition(s)? Diabetes & Once daily & 2.52 & 0.0057 \\
\hline $\begin{array}{l}\text { How many tablets or capsules (by mouth) do you take per day for this/these condition(s)? } \\
\text { Hypertension }\end{array}$ & One tablet & 2.37 & 0.0088 \\
\hline Have you run out of medication since the last visit? & No & 2.02 & 0.021 \\
\hline
\end{tabular}

Notes: Determinants, in descending order of significance, of the response "fully agree" to the question: How much do you agree with the following statement about taking your medication: I take my medication because I am used to taking it.

This unusual strategy demonstrates the relationships a feature known to be associated with adherence, perhaps between these factors illustrated by multiple correspon- in part because it has an impact on trust in the physician. dence analysis. It makes it possible to draw a new com- In this model, patients' trust in their physicians is pivotal. prehensive model of patient adherence. This model, The model delineates three entry points as modifiable illustrated in Figure 2, also considers patient age, factors for improving adherence: physician attitude, use

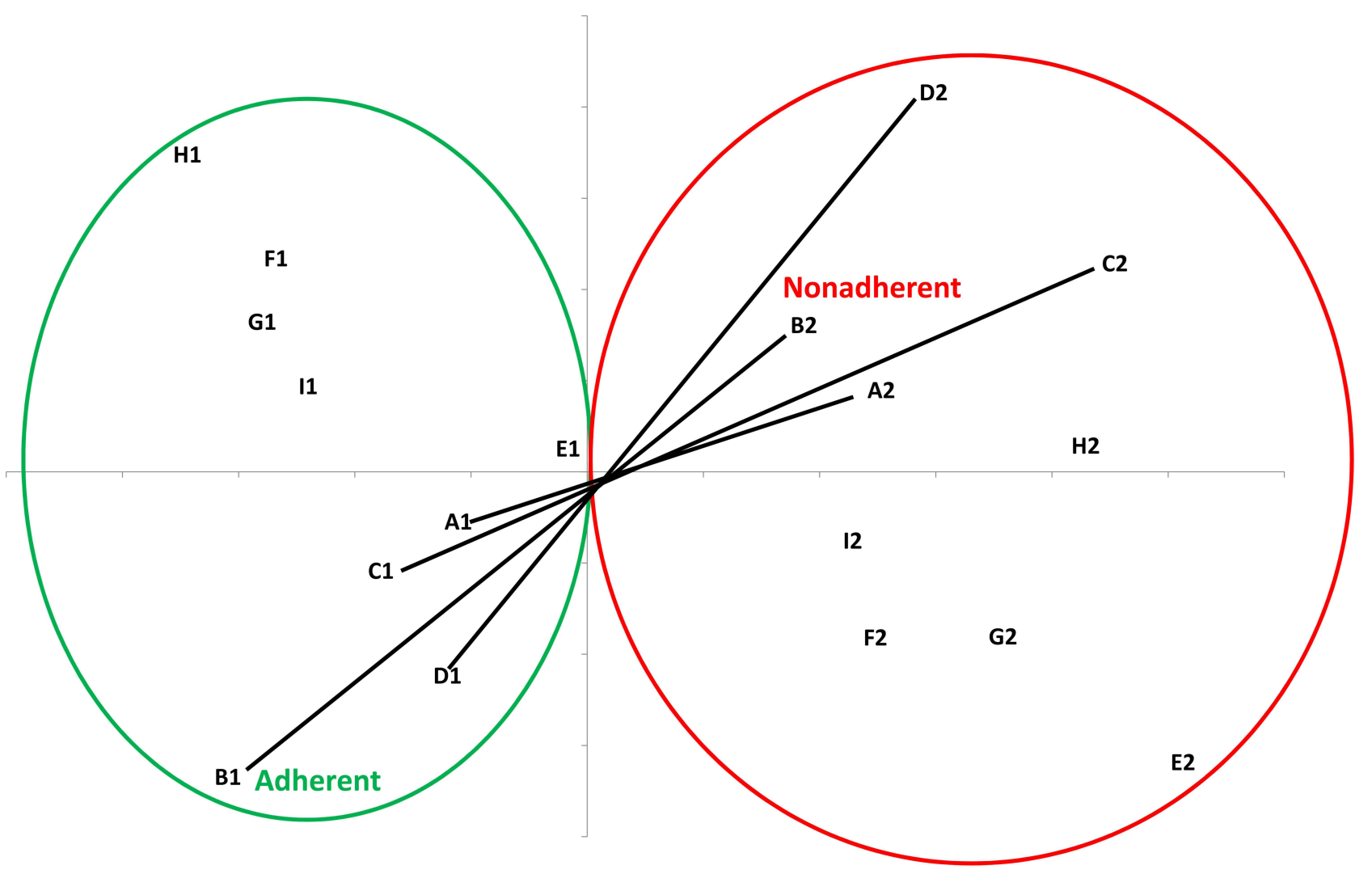

Figure I Multiple Correspondence Analysis. A: Age AI $\geq 53 /$ A2<53 years; B: Adherence BI Adherent/ B2 Nonadherent; C: Do you deliberately not take your medication? $\mathrm{CI}$ Never/C2 other answer; D: Experienced adverse effects DI No/D2 Yes; E: Generally speaking, when you have got into the habit of doing something, do you stick to it? EI Yes/E2 No; F: To what extent do you feel involved in decisions about your treatment? FI: Fully/F2: other answer; G: To what extent would you say there is a relationship of trust between you and your GP? GI: Fully /G2: other answer: H: To what extent would you say there is a relationship of trust between you and your specialist? HI: Fully/ $\mathrm{H} 2$ : other answer; I: "I take my medication because I'm used to taking it." II: Fully agree/l2: other answer. 


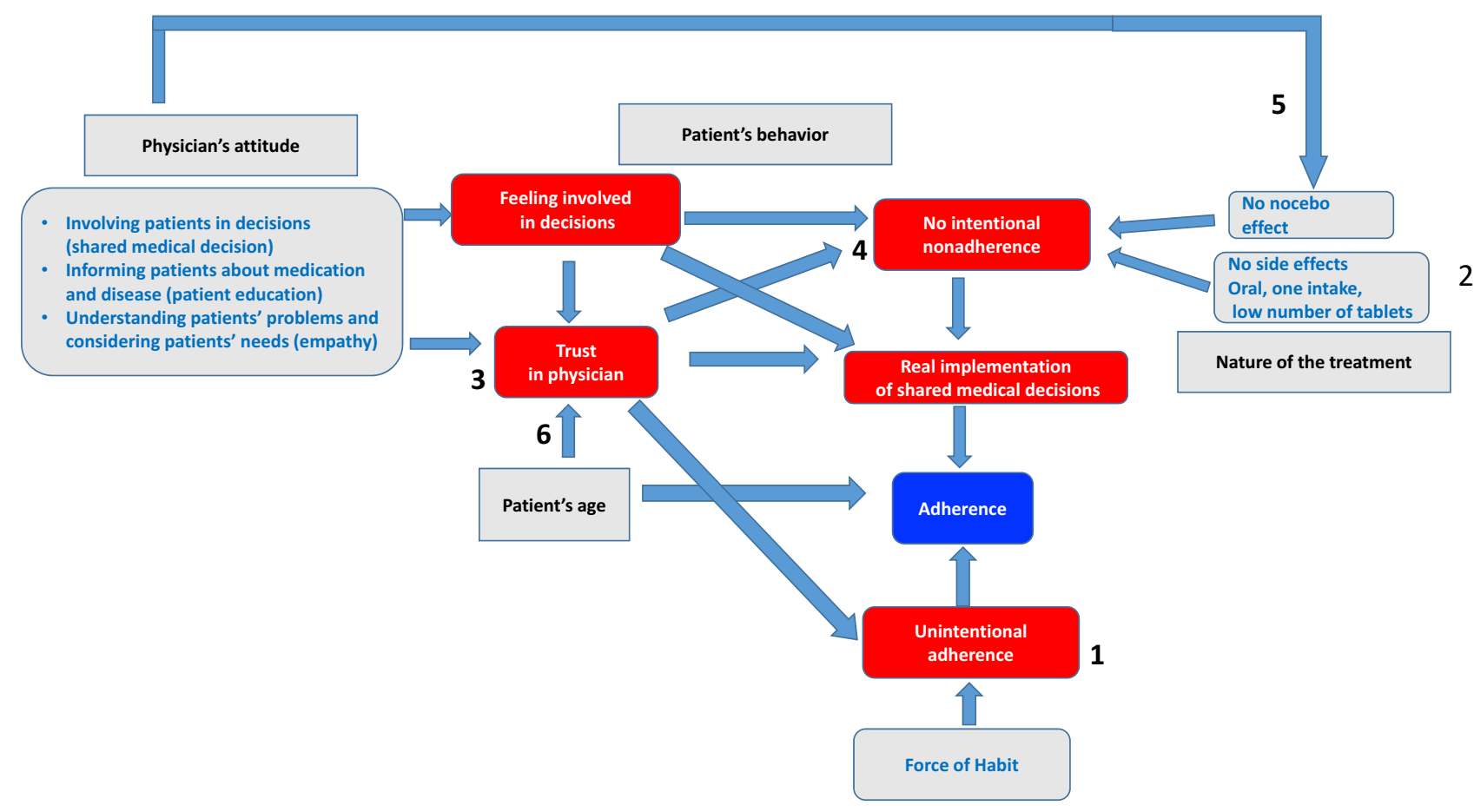

Figure $2 \mathrm{~A}$ novel model of patient adherence in taking medications. According to this model, it is possible to improve medication adherence by promoting the use of the habit (I, unintentional adherence), by playing on the nature of the treatment (2). Physician attitudes make the patient feel involved in decisions and has trust in the physician (3). These two factors combat intentional nonadherence (4). Finally, the attitudes of the physician are associated with the presence of a nocebo effect of the drug which also favors the occurrence of intentional nonadherence (5). The effect of age on trusting the doctor could form a facet of the well-known influence of age on adherence (6).

of habit, and the nature of the treatment. The model proposes that adherence can be improved not only by reducing intentional nonadherence but also by promoting unintentional adherence through habit formation.

\section{Force of habit in promoting "unintentional adherence"}

This new concept is grounded in the relationship between never deliberately omitting medication and generally sticking to habits (Table 1). In the same vein, patients who fully agree with the statement "I take my medication because I am used to taking it" answer "never" to the question "Do you sometimes deliberately not take your medication?" (Table 2).

Although more than $90 \%$ of the patients report sticking to habits, it was possible to identify factors strongly associated with that behavior $(\mathrm{P}<0.0001)$. They include feeling involved in treatment decisions, feeling informed about the pathology and the medication, positive attitudes toward physicians, being 53 and above. The same determinants were found to be associated with the use of habit in taking medication (Table 2). We speculate that patients who meet these conditions, have trust in their doctors, and feel involved in decisions may "take medication with their eyes closed" and therefore may follow their habits (Figure 2).

The association of habit strength with more than six months of treatment for hypertension could be related to the time it takes for the habit to develop. Previous studies show that the frequency of unintentional nonadherence increased during the six months after initiation of treatment, ${ }^{25}$ presumably before the formation of habit. The six months after initiating treatment, therefore, presents a window for helping patients develop the habit of taking medication; in other words, what is labeled unintentional adherence in this paper.

\section{Effect of the nature of the treatment}

Consistent with other studies, ${ }^{16,39}$ we observed an association between poor adherence with taking medications at lunch and in the evening. Multivariate analysis shows that the need to give injections is a determinant of poor adherence.

Univariate analysis of the absence of side effects revealed strong associations with adequate medication and pathology information and trust in the GP. These data suggest that some of the side effects of the drugs may be related to a nocebo 
effect. For instance, we observed that male patients reported side effects less often. This outcome is consistent with the recently described higher prevalence of nocebo effect of statin in women. ${ }^{40}$

\section{Primacy of trust}

The declaration of a mere moderate trust in a specialist was negatively associated with patient adherence in our multivariate analysis of determinants of adherence. We observed a strong association between feeling enough informed on pathology and medication and trust in the GP and the specialist $(P<0.0001$, data not shown). This finding accords with the finding that encouraging and answering questions are determinants of trust in GP. ${ }^{41}$ These data emphasize this aspect of patient education. ${ }^{42}$ The multivariate analysis revealed that feeling adequately informed about medication was an independent determinant of adherence. The multivariate analysis also disclosed that the feeling that the specialist did not take the patient's needs into account was associated with strict adherence. This outcome could be a spurious observation or an indication that strictly adherent patients accept that the specialist has prescribed a treatment that does not meet their needs.

The impact of trust on patient adherence is consistent with data in the literature. ${ }^{43-46}$ One study identifies trust as a modifiable factor for improving adherence. ${ }^{45}$ Another shows through multivariate analysis that trust in a physician determines patients' willingness to accept "one more medication." "46 The medication possession ratio, a relatively objective marker of adherence, improves when patients generally or always trust their physicians and feel involved in decisions. ${ }^{37}$

This study highlights that older patients are more often adherent. This finding is consistent with earlier studies ${ }^{3,47}$ and could relate to the appeal of immediate rewards that leads younger subjects to be less adherent with long-term therapies for chronic diseases. ${ }^{48} \mathrm{We}$ also observed that older subjects were more likely to trust their general practitioner $(P=0.006$ and 0.013 , for patients 53-70 and 70 and more, respectively, data not shown). This observation may reflect the fact that older people are generally more confident, ${ }^{49}$ especially with their physicians. ${ }^{50}$

\section{Absence of intentional nonadherence}

Table 1 shows determinants associated with the absence of intentional nonadherence by patients. These patients find that the medications are beneficial, regard their physicians positively, feel involved in treatment decisions, stick to habits, and feel informed about their diseases. Consistent with the association between intentional nonadherence and health literacy, ${ }^{26}$ patients employed as executives generally can declare reasons for not taking medications (results not shown, $P=0.022$ ). All of these findings endorse earlier studies. Intentional nonadherence associates negatively with patients' anxiety and the feeling that medication is necessary and positively with concerns about medication ${ }^{51}$ and dissatisfaction with treatment, including relations with medical staff. ${ }^{52}$

Finally, the MCA shows the proximity of several domains represented by the lines describing them: 1. age (A1-A2), general adherence (B1-B2), intentional nonadherence $(\mathrm{C} 1-\mathrm{C} 2)$, and absence or presence of side effects (D1-D2); 2. the feeling of being involved in decisions (F1-F2) and trusting the GP and the specialist (G1-G2, and $\mathrm{H} 1-\mathrm{H} 2$, respectively); 3 . using habit (I1-I2) and general adherence to habit (E1-E2).

\section{Strengths and limitations of the study}

The main strength of this study is in investigating disparate research objects simultaneously to show their connections. Its secondary strength is the use of a panel of respondents who rarely answer health questionnaires and not patients participating in health panels, thereby eliminating selection bias. Finally, our method assures that no data are missing because patients could not skip questions. That our data are often derived from univariate analyses is not a limitation. Conventional over-emphasis on multivariate analyses forgets that the two pursue different objectives: the latter seeks the independent nature of criteria, whereas univariate studies identify them. ${ }^{53}$

Nonetheless, our study has limitations. Apart from the adherence questionnaire, ${ }^{36}$ our overall questionnaire has not been validated formally. We did not conduct a pilot study to verify whether the questions were comprehensible as the questionnaire items had either been used in other studies in the literature ${ }^{29,37}$ or in the first author's published work. ${ }^{30,54,55}$ Some constructs are based on only one question, but measures using a single question may be as valid as multi-item concrete measures. ${ }^{56}$ Our study was conducted in a single country, which limits the generalizability of results by disregarding cultural influences. Like all studies of this type, ours is based on declarative elements. However, the fact that its respondents belonged to 
a consumer panel rather than a patient panel and responded online could limit the well-known social desirability bias. ${ }^{57}$ Furthermore, answers to early questions might influence answers to subsequent questions, rendering the connections we draw illusory. However, those connections may arguably reflect the mental correspondence that patients draw between construals. ${ }^{34}$ It is tempting to speculate that some of these connections have a neurobiological basis. Finally, one could ask whether the questionnaire used in this study is still relevant considering the possibility of a drastic change in patient attitudes toward adherence to long-term therapies due to the presence of smart and advanced treatment technologies. However, adherence is a general issue since Hippocrates, ${ }^{58}$ which links it to the human nature. The first author recently published an article on the psychology of decision-making in glucose monitoring (self-monitoring of blood glucose, continuous glucose monitoring, pump therapy, and artificial pancreas), demonstrating that the psychological issues related to adherence are exactly the same as for drugs and include intentionality. ${ }^{59}$

\section{Conclusion}

Although interventions to improve adherence are often disappointing, multifactorial interventions seem effective. ${ }^{60}$ Recently, Peh et al proposed a unified description after analyzing 102 conceptual frameworks that have been proposed to explain medication adherence/nonadherence. This description takes the form of a five-part "donut" of all factors that may be considered determinants of adherence/nonadherence: patient-related factors, medication-related factors, condition-related factors, health system-related factors, and socioeconomic factors. ${ }^{22}$ The originality of the model presented in our paper is vested in its demonstration of the existence of interconnections between the first three blocks: physician attitudes, patient characteristics, and nature of the treatment. Our model shows that it is necessary to avoid "intentional nonadherence" by playing on the nature of the treatment and the shared medical decision. It is equally essential to help patients develop "unintentional adherence" based on habit, a concept proposed in this paper. We also suggest a link between the attitudes of doctors and the appearance of the nocebo effect, which can, like real side effects, cause intentional nonadherence.

The proposed model should offer major implications for the practice of medicine as it clearly demonstrates the impact of physicians' attitudes, both on patient adherence and on the possibility of using habits, ie, unintentional adherence. The attitude of doctors, involvement of patients in decisions (shared decision-making), information on medications and pathology (patient education), understanding patient problems, and considering their needs (empathy) should increasingly find place in medical curricula.

\section{Acknowledgments}

The authors are grateful to Mylan, a Viatris company that supported this study, and to Vivactis for its role in the organization of this study.

\section{Author contributions}

All the authors are academics who participated in the initial design of the study and in the analysis of the data in the framework of a scientific board. GR designed the final analysis strategy and directed the statistical analysis, which was performed by LB, and wrote the manuscript. All authors contributed to data analysis, drafting or revising the article, have agreed on the journal to which the article will be submitted, gave final approval of the version to be published, and agree to be accountable for all aspects of the work.

\section{Funding}

This work was supported by a grant from Mylan-Viatris in 2019. This grant funded Vivactis, a Clinical Research Organization, which organized the collection and preliminary analysis of the data presented and discussed by the scientific board of academics. The author(s) disclosed the receipt of honoraria for their participation to this scientific board. Mylan-Viatris was not involved in the interpretation of the data and did not impose any restrictions on their publication.

\section{Disclosure}

All authors have completed the Unified Competing Interest form and declare no support from any organization for the submitted work, except for the fees related to the participation to the study's scientific board.

GR declares having received honoraria for his participation in symposia organized by Novo-Nordisk, Lilly, Novartis, Sanofi-Aventis, Merck-Serono, GSK, Ipsen, Abbott-Pharma, BMS, Pfizer, Roche-Pharma, RocheDiagnostics, Abbott-Diagnostics, Lifescan, Bayer Diagnostics, Dexcom, BioGen, AbbVie, Servier, Novartis, Takeda, and Mylan-Viatris, and for involvement in the boards of Lifescan, Bayer Diagnostics, Lilly, Sanofi- 
Aventis, Mylan-Viatris, Novo-Nordisk, Abbott, Takeda, and Timkl.

LB has no conflicts of interest to declare.

EB reports personal fees from MSD, Akcea, Servier, Sanofi-Aventis, Amgem, Genfit, Regeneron, MylanViatris, Danone, Silence Therapeutics, Novartis, and Ionis pharmaceuticals, and grants and personal fees from Aegerion Amryt.

JPK reports having received fees for consulting or lectures from Novartis, Novo-Nordisk, Mylan-Viatris, Meda Pharma, Bayer, Boehringer Ingelheim, and GlaxoSmithKline, outside the purview of the submitted work.

MF reports having received consulting fees and/or honoraria from Abbott, Amarin, Amgen, Austell, Merck and Co, Daîchi-Sankyo, Kowa, MSD, Mylan, Pfizer, Sanofi/ Regeneron, and Servier.

JJM reports personal fees from Pfizer, Servier, BMS, RESMED, and Mylan-Viatris.

$\mathrm{BCV}$ reports having received consulting fees and/or honoraria from Boehringer Ingelheim, Novo-Nordisk, Mylan-Viatris, and Servier, and grants from NovoNordisk, Mylan-Viatris, and Sanofi-Aventis, outside the submitted work.

The authors report no other potential conflicts of interest for this work.

\section{References}

1. WHO Report. Adherence to Long-Term Therapies, Evidence for Action. Eduardo SE, ed. World Health Organization; 2003.

2. Vrijens B, De Geest S, Hughes DA, et al. A new taxonomy for describing and defining adherence to medications. $\mathrm{Br} J$ Clin Pharmacol. 2012;73(5):691-705. doi:10.1111/j.13652125.2012.04167.x

3. Briesacher BA, Andrade SE, Fouayzi H, Chan KA. Comparison of drug adherence rates among patients with seven different medical conditions. Pharmacotherapy. 2008;28(4):437-443. doi:10.1592/ phco.28.4.437

4. Vrijens B, Antoniou S, Burnier M, de la Sierra A, Volpe M. Current situation of medication adherence in hypertension. Front Pharmacol. 2017;8:100. doi:10.3389/fphar.2017.00100

5. Peacock E, Krousel-Wood M. Adherence to antihypertensive therapy. Med Clin North Am. 2017;101(1):229-245. doi:10.1016/j. mena.2016.08.005

6. George M. Adherence in asthma and COPD: new strategies for an old problem. Respir Care. 2018;63(6):818-831. doi:10.4187/respcare.05905

7. Claros MP, Messa CVM, García-Perdomo HA. Adherence to oral pharmacological treatment in cancer patients: systematic review. Oncol Rev. 2019;13(1):402. doi:10.4081/oncol.2019.402

8. Fatoye F, Smith P, Gebrye T, Yeowell G. Real-world persistence and adherence with oral bisphosphonates for osteoporosis: a systematic review. BMJ Open. 2019;9(4):e027049. doi:10.1136/bmjopen-2018-027049

9. Curtis SE, Boye KS, Lage MJ, Garcia-Perez LE. Medication adherence and improved outcomes among patients with type 2 diabetes. $\mathrm{Am}$ J Manag Care. 2017;23(7):e208-e214. PMID: 28850793.
10. Khunti K, Seidu S, Kunutsor S, Davies M. Association between adherence to pharmacotherapy and outcomes in type 2 diabetes: a meta-analysis. Diabetes Care. 2017;40(11):1588-1596. doi:10.2337/dc16-1925

11. Ho PM, Rumsfeld JS, Masoudi FA, et al. Effect of medication non-adherence on hospitalization and mortality among patients with diabetes mellitus. Arch Intern Med. 2006;166:1836-1841.

12. Mennini FS, Marcellusi A, von der Schulenburg JM, et al. Cost of poor adherence to anti-hypertensive therapy in five European countries. Eur $J$ Health Econ. 2015;16(1):65-72. doi:10.1007/s10198-013-0554-4

13. Giugliano D, Maiorino MI, Bellastella G, Esposito K. Glycemic control in type 2 diabetes: from medication non-adherence to residual vascular risk. Endocrine. 2018;61(1):23-27. PMID: 29322300. doi:10.1007/s12020-017-1517-9

14. Burnier M, Egan BM. Adherence in hypertension. Circ Res. 2019;124(7):1124-1140. PMID: 30920917. doi:10.1161/ CIRCRESAHA.118.313220

15. Liberopoulos EN, Florentin M, Mikhailidis DP, Elisaf MS Compliance with lipid-lowering therapy and its impact on cardiovascular morbidity and mortality. Expert Opin Drug Saf. 2008;7 (6):717-725. PMID: 18983218. doi:10.1517/14740330802396984

16. Leslie KH, McCowan C, Pell JP. Adherence to cardiovascular medication: a review of systematic reviews. J Public Health. 2019;41(1): e84-e94. doi:10.1093/pubmed/fdy088

17. Chan AHY, Cooper V, Lycett H, Horne R. Practical barriers to medication adherence: what do current self- or observer-reported instruments assess? Front Pharmacol. 2020;11:572. doi:10.3389/ fphar.2020.00572

18. Gast A, Mathes T. Medication adherence influencing factors-an (updated) overview of systematic reviews. Syst Rev. 2019;8(1):112. PMID: 31077247; PMCID: PMC6511120. doi:10.1186/s13643-0191014-8

19. Genberg BL, Lee Y, Rogers WH, Wilson IB. Four types of barriers to adherence of antiretroviral therapy are associated with decreased adherence over time. AIDS Behav. 2015;19(1):85-92. doi:10.1007/ s10461-014-0775-2

20. Shubber Z, Mills EJ, Nachega JB, et al. Patient-reported barriers to adherence to antiretroviral therapy: a systematic review and meta-analysis. PLoS Med. 2016;13(11):e1002183. doi:10.1371/journal.pmed.1002183

21. Sinnott SJ, Buckley C, O'Riordan D, Bradley C, Whelton H. The effect of copayments for prescriptions on adherence to prescription medicines in publicly insured populations: a systematic review and meta-analysis. PLoS One. 2013;8(5):e64914. doi:10.1371/journal.pone.0064914

22. Peh KQE, Kwan YH, Goh H, et al. An adaptable framework for factors contributing to medication adherence: results from a systematic review of 102 conceptual frameworks. J Gen Intern Med. 2021:1-2. PMID: 33660211. doi:10.1007/s11606-021-06648-1.

23. Lehane E, McCarthy G. Intentional and unintentional medication non-adherence: a comprehensive framework for clinical research and practice? A discussion paper. A discussion paper. Int J Nurs Stud. 2007;44(8):1468-1477. doi:10.1016/j.ijnurstu.2006.07.010

24. Thorneloe RJ, Griffiths CEM, Emsley R, Ashcroft DM, Cordingley L. British association of dermatologists biologic interventions register, psoriasis stratification to optimise relevant therapy study groups. Intentional and unintentional medication nonadherence in psoriasis: the role of patients' medication beliefs and habit strength. J Invest Dermatol. 2018;138:785-794.

25. Molloy GJ, Messerli-Bürgy N, Hutton G, Wikman A, Perkins-Porras L, Steptoe A. Intentional and unintentional non-adherence to medications following an acute coronary syndrome: a longitudinal study. J Psychosom Res. 2014;76(5):430-432. doi:10.1016/j.jpsychores.2014.02.007

26. Lindquist LA, Go L, Fleisher J, Jain N, Friesema E, Baker DW. Relationship of health literacy to intentional and unintentional non-adherence of hospital discharge medications. J Gen Intern Med. 2012;27(2):173-178. doi:10.1007/s11606-011-1886-3 
27. Gadkari AS, McHorney CA. Unintentional non-adherence to chronic prescription medications: how unintentional is it really? BMC Health Serv Res. 2012;12(1):98-109. doi:10.1186/1472-6963-12-98

28. Triandis HC. Values, attitudes and interpersonal behavior. Nebr Symp Motiv. 1980;27:195-259.

29. Phillips LA, Cohen J, Burns E, Abrams J, Renninger S. Selfmanagement of chronic illness: the role of 'habit' versus reflective factors in exercise and medication adherence. J Behav Med. 2016;39 (6):1076-1091. doi:10.1007/s10865-016-9732-z

30. Reach G, Pellan M, Crine A, Touboul C, Ciocca A, Djoudi Y. Holistic psychosocial determinants of adherence to medication in people with type 2 diabetes. Diabetes Metab. 2018;44(6):500-507. doi:10.1016/j.diabet.2018.06.001

31. Reach G. The role of habit in therapeutic adherence. Diabet Med. 2005;22(4):415-420. doi:10.1111/j.1464-5491.2004.01449.x

32. Searle J. Intentionality: An Essay in the Philosophy of Mind. New York: Cambridge University Press; 1983.

33. Kahneman D. Thinking, Fast and Slow. Farrar, Straus \& Giroux; 2011.

34. Reach G. The Mental Mechanisms of Patient Adherence to Long Term Therapies, Mind and Care. Foreword by Pascal Engel. Springer; 2015.

35. Norstat Panel Privacy Policy. Available from: https://www.norstatpa nel.com/en/privacy-policy. Accessed July 14, 2021.

36. Girerd X, Hanon O, Anagnostopoulos K, Ciupek C, Mourad JJ, Consoli S. Evaluation de l'observance du traitement antihypertenseur par un questionnaire: mise au point et utilisation dans un service spécialisé. Presse Med. 2001;30:1044-1048.37.

37. Ratanawongsa N, Karter AJ, Parker MM, et al. Communication and medication adherence: the Diabetes Study of Northern California. JAMA Intern Med. 2013;173(3):210-218. doi:10.1001/ jamainternmed.2013.1216

38. Esomar Guideline for Online Research. Available from: https://www. esomar.org/uploads/public/knowledge-and-standards/codes-andguidelines/ESOMAR_Guideline-for-online-research.pdf. Accessed March 15, 2021.

39. Kawalec P, Holko P, Gawin M, Pilc A. Effectiveness of fixed-dose combination therapy in hypertension: systematic review and meta-analysis. Arch Med Sci. 2018;14(5):1125-1136. doi:10.5114/ aoms.2018.77561

40. Moon J, Cohen Sedgh R, Jackevicius CA. Examining the nocebo effect of statins through statin adverse events reported in the food and drug administration adverse event reporting system. Circ Cardiovasc Qual Outcomes. 2021;14(1):e007480. PMID: 33161769. doi:10.1161/ CIRCOUTCOMES.120.007480

41. Thom DH. Stanford trust study physicians. physician behaviors that predict patient trust. J Fam Pract. 2001;50:323-328.

42. Glasgow RE, Emont S, Miller DC. Assessing delivery of the five "As" for patient-centered counseling. Health Promot Int. 2006;21 (3):245-255. doi:10.1093/heapro/da1017

43. Safran DG, Taira DA, Rogers WH, Kosinski M, Ware JE, Tarlov AR. Linking primary care performance to outcomes of care. J Fam Pract. 1998;47:213-220.

44. Bonds DE, Camacho F, Bell RA, Duren-Winfield VT, Anderson RT, Goff DC. The association of patient trust and self-care among patients with diabetes mellitus. BMC Fam Pract. 2004;5(1):26. doi:10.1186/1471-2296-5-26
45. Nguyen GC, LaVeist TA, Harris ML, Datta LW, Bayless TM, Brant SR. Patient trust-in-physician and race are predictors of adherence to medical management in inflammatory bowel disease. Inflamm Bowel Dis. 2009;15(8):1233-1239. doi:10.1002/ibd.20883

46. Zikmund-Fisher BJ, Hofer TP, Klamerus ML, Kerr EA. First things first: difficulty with current medications is associated with patient willingness to add new ones. Patient. 2009;2(4):221-231. doi:10.2165/11313850-000000000-00000

47. Lee R, Taira DA. Adherence to oral hypoglycemic agents in Hawaii. Prev Chronic Dis. 2005;2:A09.

48. Reach G. Temporality in chronic diseases and adherence to long-term therapies: from philosophy to science and back. Diabetes Metab. 2019;45(5):419-428. doi:10.1016/j.diabet.2018.11.002

49. Bailey PE, Leon T. A systematic review and meta-analysis of age-related differences in trust. Psychol Aging. 2019;34(5):674-685. doi:10.1037/pag0000368

50. Zhao DH, Rao KQ, Zhang ZR. Patient trust in physicians: empirical evidence from Shanghai, China. Chin Med J. 2016;129(7):814-818. doi:10.4103/0366-6999.178971

51. Park Y, Park YH, Park KS. Determinants of non-adherences to long-term medical therapy after myocardial infarction: a cross-sectional study. Int J Environ Res Public Health. 2020;17 (10):3585. doi:10.3390/ijerph17103585

52. Iihara N, Nishio T, Okura M, et al. Comparing patient dissatisfaction and rational judgment in intentional medication non-adherence versus unintentional nonadherence. J Clin Pharm Ther. 2014;39(1):45-52. doi:10.1111/jept.12100

53. Johnson RJ. Finding the truth: multivariable analysis and the assassination of Abraham Lincoln. $J R$ Coll Phys Edinb. 2018;48 (2):153-154. doi:10.4997/JRCPE.2018.210

54. Reach G. Obedience and motivation as mechanisms for adherence to medication. A study in obese type 2 diabetic patients. Patient Prefer Adherence. 2011;5:523-531. doi:10.2147/PPA.S24518

55. Reach G, Chenuc G, Maigret P, Elias-Billon I, Martinez L, Flipo RM. Implication of character traits In adherence to treatment in people with gout: a reason for considering non-adherence as a syndrome. Patient Prefer Adherence. 2019;7(13):1913-1926. doi:10.2147/PPA. S227329

56. Bergkvist L, Rossiter JR. The predictive validity of multiple-Item versus single-item measures of the same constructs. J Mark Res. 2007;44(2):175-184. doi:10.1509/jmkr.44.2.175

57. Collins M, Shattell M, Thomas SP. Problematic interviewee behaviors in qualitative research. West J Nurs Res. 2005;27(2):188-199. doi:10.1177/0193945904268068

58. Hippocrates. Decorum, 14. In: Jones WHS, ed. Hippocrates Volume II. William Heinemann; 1923:267-302.

59. Reach G. Decisions in the psychology of glucose monitoring. $J$ Diabetes Sci Technol. 2019;13(6):1169-1174. doi:10.1177/ 193296819854109

60. Nieuwlaat R, Wilczynski N, Navarro $\mathrm{T}$, et al. Interventions for enhancing medication adherence. Cochrane Database Syst Rev. 2014;2014:CD000011. 


\section{Publish your work in this journal}

Patient Preference and Adherence is an international, peer-reviewed, open access journal that focusing on the growing importance of patient preference and adherence throughout the therapeutic continuum. Patient satisfaction, acceptability, quality of life, compliance, persistence and their role in developing new therapeutic modalities and compounds to optimize clinical outcomes for existing disease states are major areas of interest for the journal. This journal has been accepted for indexing on PubMed Central. The manuscript management system is completely online and includes a very quick and fair peer-review system, which is all easy to use. Visit http:// www.dovepress.com/testimonials.php to read real quotes from published authors.

Submit your manuscript here: https://www.dovepress.com/patient-preference-and-adherence-journal 